\title{
Effect of Remifentanil on Seizure Duration and Patient Experience in Electroconvulsive Therapy
}

Garth T., Nagore D., Jimeno J.P., Bilbao A., Belamaric Z.

\section{Background and Goal of Study}

In April 1938, Ugo Cerletti and Lucio Bini pioneered the use of electricity to induce seizures in a paranoid, schizophrenic man found wandering the streets of Rome. After 11 sessions he was declared successfully cured and, proclaiming his enthusiasm for the new treatment, was able to return to work.

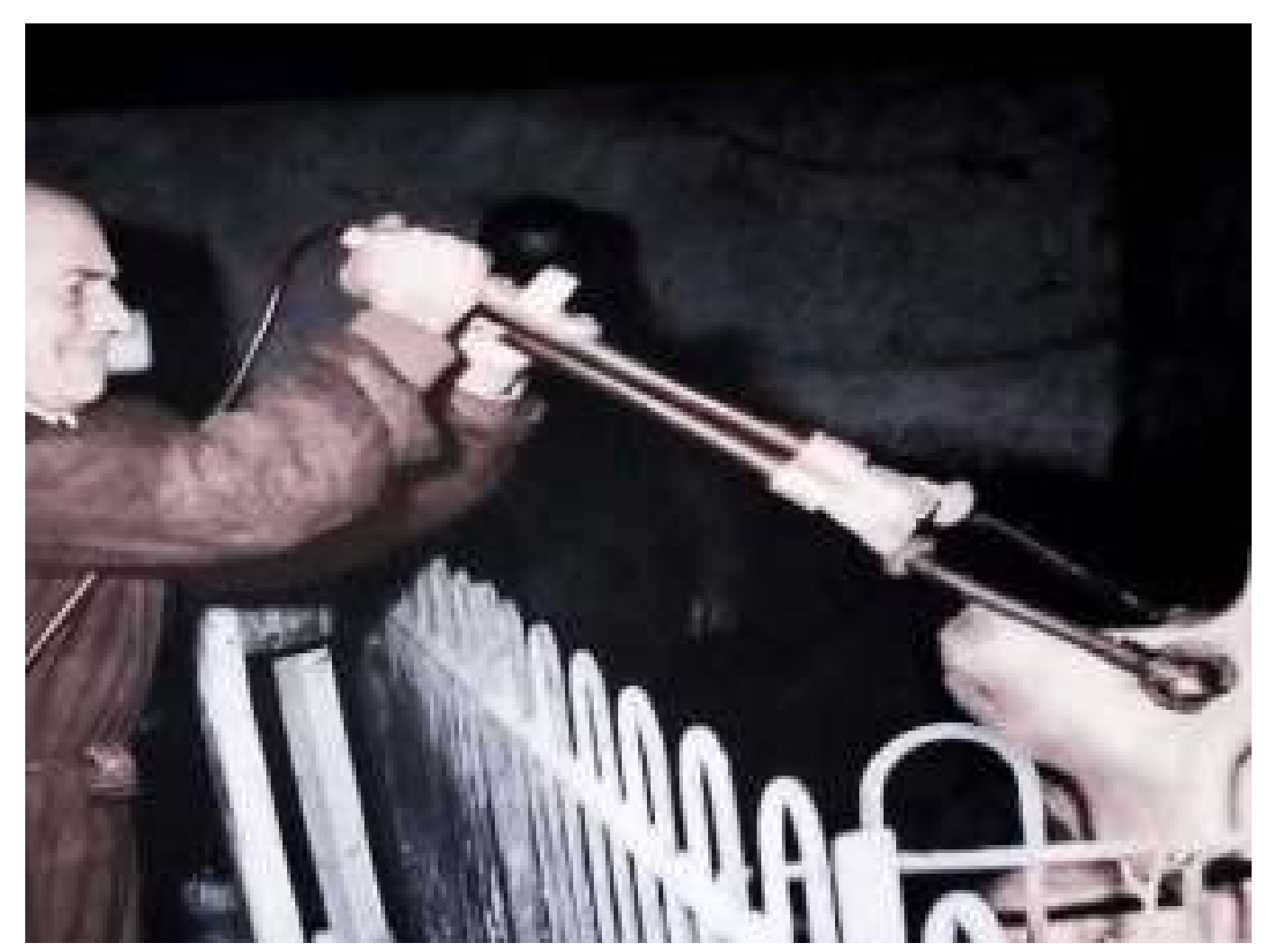

Fig. 1: Ugo Cerletti first came up with the idea to use electricity to induce seizures in humans after watching pigs being stunned prior to being butchered.

There have been many advances in ECT since, most notably the introduction of 'Modified ECT' incorporating the use of anaesthesia and muscle relaxants to minimise the risk of long bone fractures and dislocations.

Seizure durations of $15 \mathrm{~s}$ to $120 \mathrm{~s}$ are known to give the best outcomes from ECT. The use of remifentanil conveys the likely advantages of decreasing seizure threshold and increasing seizure duration. This study aims to evaluate the effects of using remifentanil in combination with thiopentone on seizure duration and patient satisfaction in ECT.

\section{Materials and Methods}

The study was conducted at the Royal London Hospital. 20 patients receiving thiopentone $3 \mathrm{mg} / \mathrm{kg}$ and 20 receiving thiopentone $3 \mathrm{mg} / \mathrm{kg}$ and remifentanil $1 \mathrm{mcg} / \mathrm{kg}$ were surveyed. All patients received an ECT dose of $225 \mathrm{~V}$ via bilaterally placed electrodes and succinylcholine $0.4 \mathrm{mg} / \mathrm{kg}$.

Both visual and EEG seizure durations were recorded and patients were asked to rate their satisfaction on a scale from 1 to 10 before discharge. A student unpaired $\mathrm{T}$ test was used to calculate $\mathrm{p}$ values.

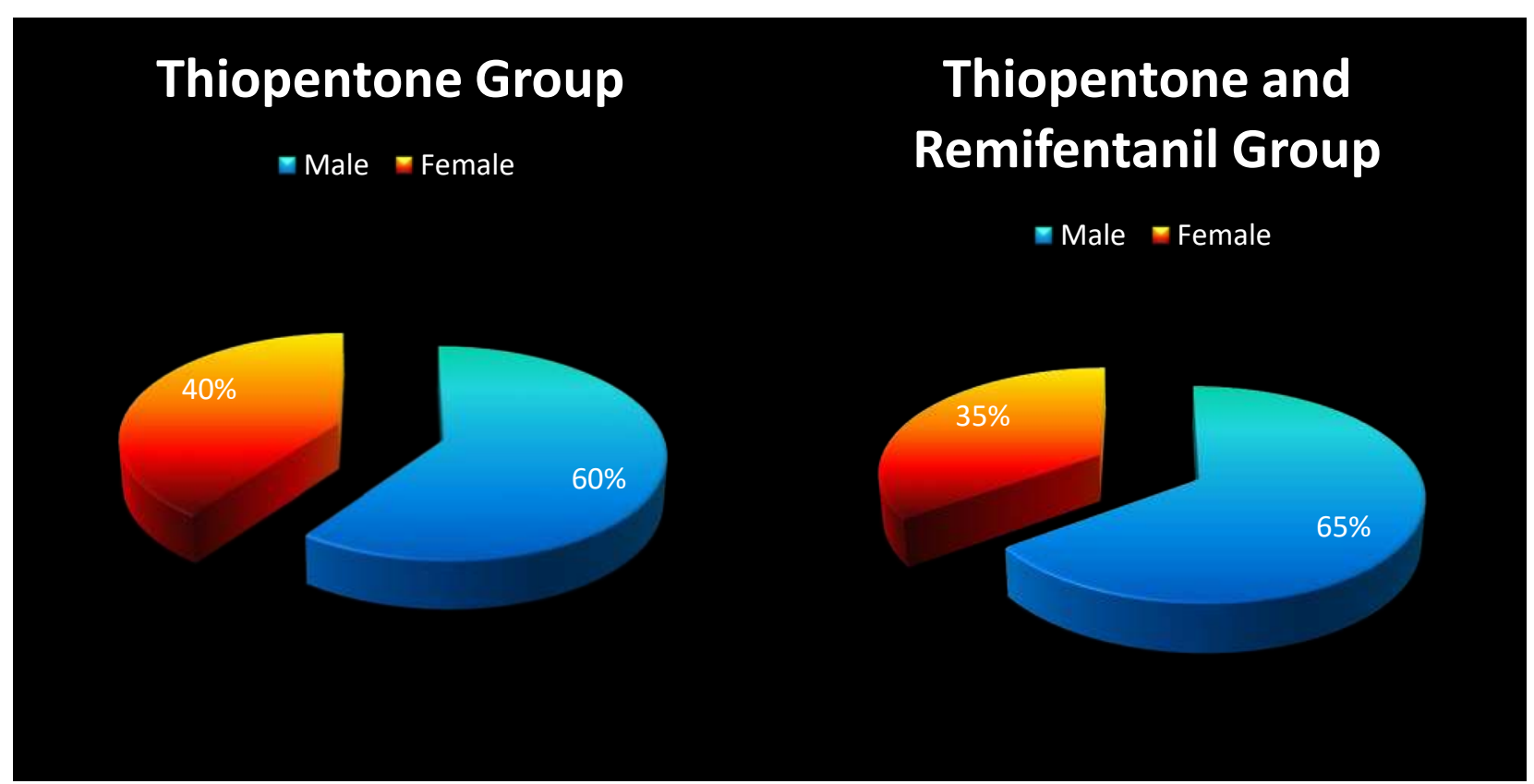

\section{$\underline{\text { Results and Discussion }}$}

The addition of remifentanil was found to increase the mean visible seizure duration from $14.5 \mathrm{~s}$ to $23.7 \mathrm{~s}$ (95\% confidence interval 5.71 to $12.79, \mathrm{P}<0.0001$ ) and mean EEG seizure duration from 19.6s to $29.0 \mathrm{~s}$ (95\% confidence interval 5.81 to $13.09, \mathrm{P}<0.0001$ ). Mean patient satisfaction score rose from 6.6 to 7.6 with the use of remifentanil $(95 \%$ confidence interval -0.62 to $2.72, \mathrm{P} 0.2118$ ). 4 patients reported myalgia and 1 reported trauma to their lip when thiopentone alone was used. Fewer patients reported adverse effects when remifentanil was given with 1 reporting myalgia, 1 nausea and 1 trauma to their lip.
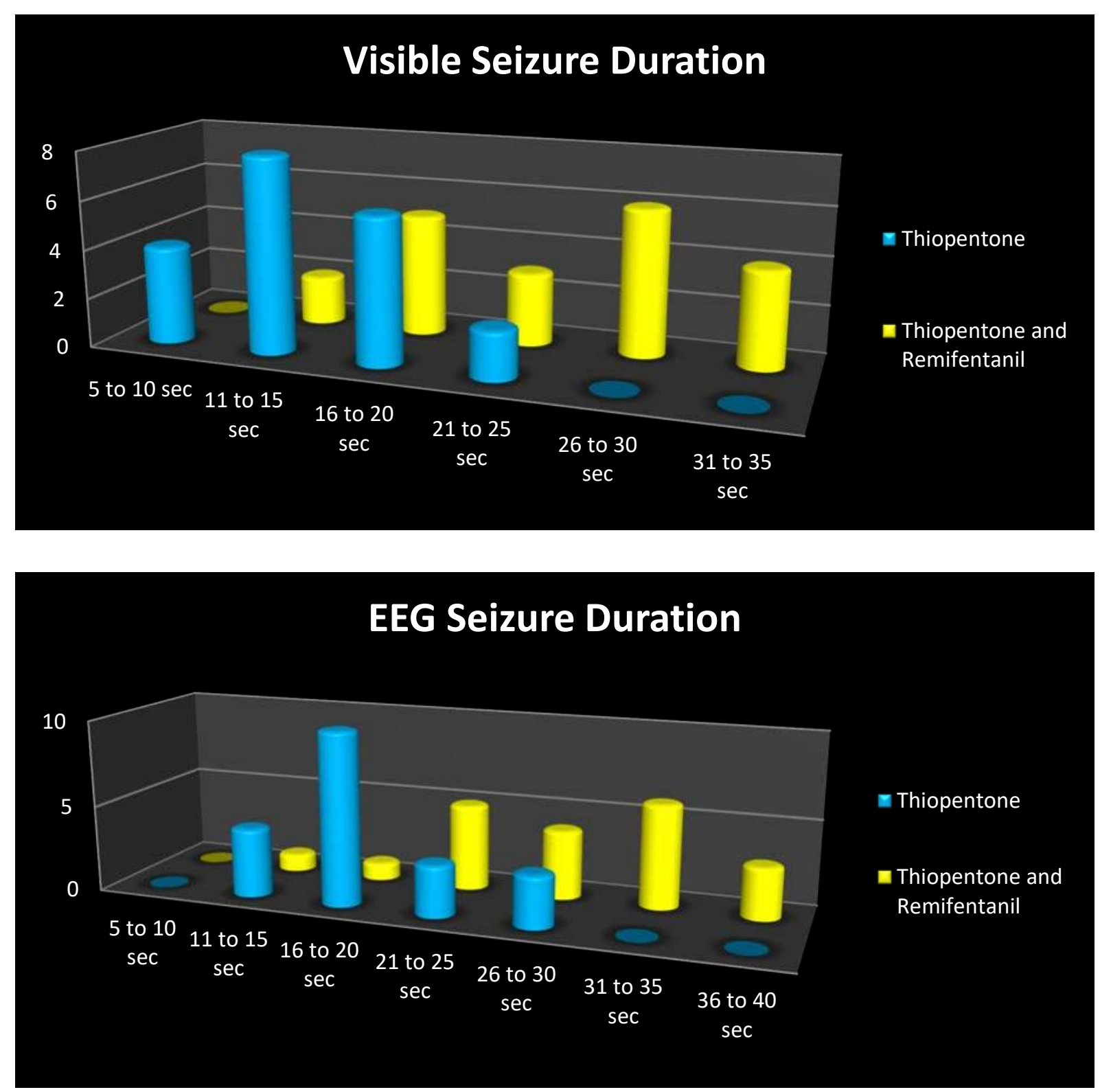

\section{$\underline{\text { Conclusion }}$}

This study suggests that the addition of remifentanil does significantly increase seizure duration in ECT. Although the improvement in patient satisfaction was not significant, fewer patients complained of myalgia after receiving remifentanil. It is clear that remifentanil does have a role in anaesthesia for ECT, however, the overall effect on patient outcomes still remains to be accurately quantified.

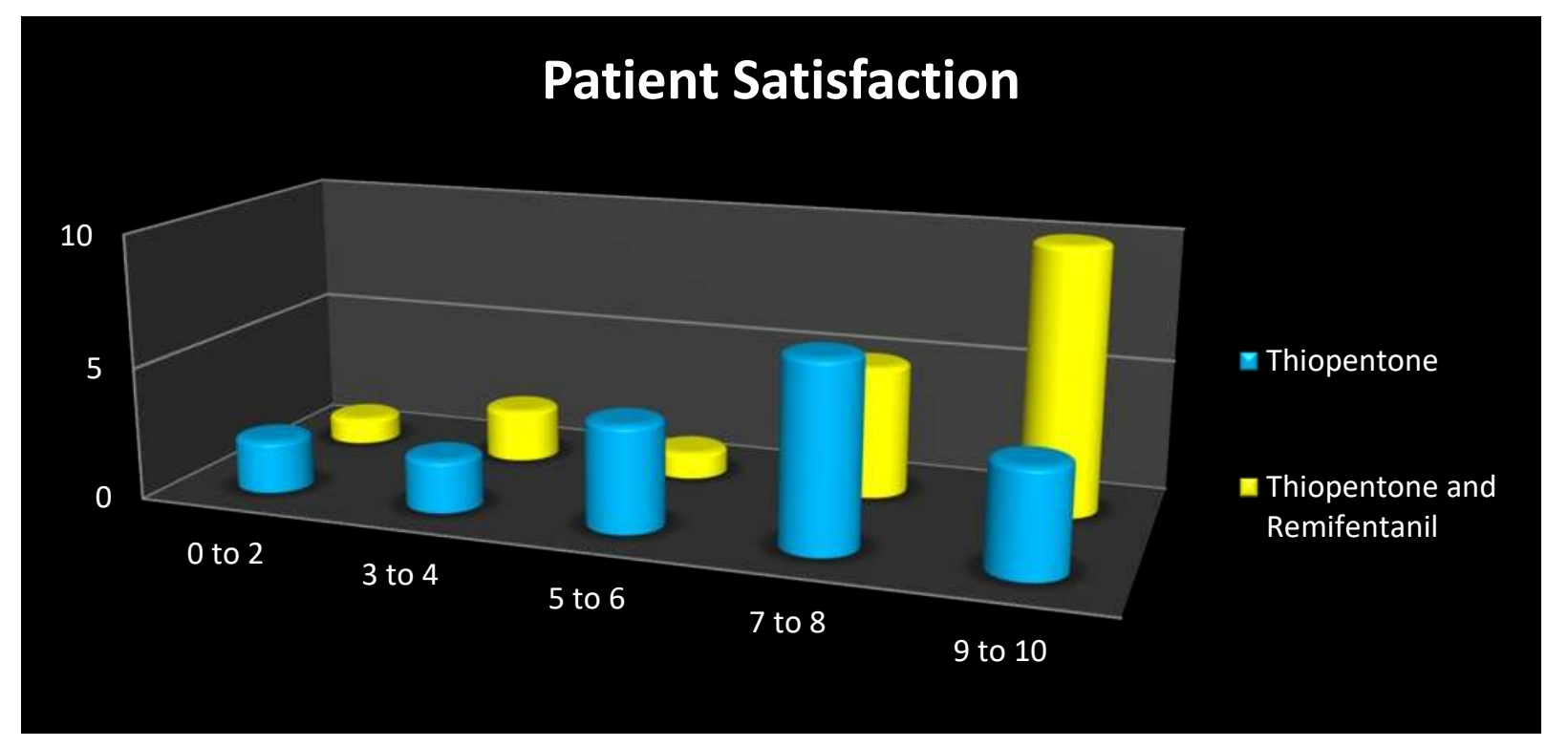

\section{Barts Health WHS}

